\title{
Knowledge, Attitude, and Beliefs of Communities and Health Staff about Echinococcus granulosus Infection in Selected Pastoral and Agropastoral Regions of Uganda
}

\author{
Emmanuel Othieno, ${ }^{1}$ Michael Ocaido, ${ }^{2}$ Ezekiel Mupere, ${ }^{3}$ Leonard Omadang, \\ Peter Oba, ${ }^{2,4}$ and Andrew Livex Okwi iD ${ }^{1}$ \\ ${ }^{1}$ Department of Pathology, School of Biomedical Sciences, College of Health Sciences, Makerere University, \\ P.O. Box 7072, Kampala, Uganda \\ ${ }^{2}$ Department of Wild Life, School of Veterinary Medicine and Animal Resources, College of Veterinary Medicine, \\ Animal Resources and Biosecurity, Makerere University, P.O. Box 7062, Kampala, Uganda \\ ${ }^{3}$ Department of Pediatrics, School of Medicine, College of Health Sciences, Makerere University, P.O. Box 7072, Kampala, Uganda \\ ${ }^{4}$ National Agricultural Research Organization, Abi Zonal Agricultural Research and Development Institute, \\ P.O. Box 219, Arua, Uganda
}

Correspondence should be addressed to Andrew Livex Okwi; liajd17@gmail.com

Received 20 September 2017; Revised 21 February 2018; Accepted 29 March 2018; Published 13 May 2018

Academic Editor: José F. Silveira

Copyright (C) 2018 Emmanuel Othieno et al. This is an open access article distributed under the Creative Commons Attribution License, which permits unrestricted use, distribution, and reproduction in any medium, provided the original work is properly cited.

A descriptive cross-sectional survey was done to determine knowledge, attitudes, and beliefs of the communities and health workers about cystic echinococcosis (CE) in pastoral region of Northeastern (NE) and agropastoral regions of Eastern (E) and Central (C) Uganda. Overall a total of 1310 participants were interviewed. Community respondents from NE region were more aware of CE infection than those from Eastern (OR 4.85; CI: 3.60-6.60; $p<0.001$ ) and Central (OR 5.73; CI: 4.22-7.82; $p<0.001$ ) regions. $19.8 \%$ of the respondents from EA region had positive attitude towards visiting witch doctors for treatment compared with $62.0 \%$ and $60.4 \%$ from NE and Central regions, respectively $(p<0.001)$. Notably, the awareness of CE increased with level of education $(p<0.001)$. There was no statistical difference between male and female respondents as far as awareness of CE was concerned ( $p>0.05$ ). 51.7\% of the community respondents from Central believed CE is caused by witchcraft, compared with $31.3 \%$ and $14.3 \%$ from NE and EA regions, respectively $(p<0.001)$. There was no statistical difference between health staff regarding their knowledge, attitude, and beliefs about CE infection $(p>0.05)$. None of the participants knew his/her CE status. The communities need to be sensitized about CE detection, control, and management and health staff need to be trained on CE diagnosis.

\section{Introduction}

According to World Health Organization (WHO) [1] cystic echinococcosis (CE) is a neglected zoonotic infection found throughout the world and is associated with high morbidity and mortality in poor resource countries especially in pastoral communities in Africa (Macpherson et al. [2]). In Uganda, the prevalence of CE has been found to vary between pastoral and agropastoral communities, with pastoral communities being at higher risk than agropastoral communities (Othieno et al. [3]). High prevalence of CE has equally been reported in livestock (Chamai et al. [4] and Magambo et al. [5]) and in dogs (Inangolet et al. [6] and Oba et al. [7]). Cystic echinococcosis is caused by a species of Echinococcus, namely, Echinococcus granulosus, whose definitive hosts are the carnivores such as dogs. Usually dogs become infected with Echinococcus granulosus by eating infected internal organs such as liver and lungs from dead animals that contain tape worm embryos. The dogs pass out tapeworm eggs in their stool, which can cause infection in other animals and/or in humans who accidentally swallow the eggs. In humans, Echinococcus granulosus forms slow-growing 
cysts (called hydatid cysts) in different organs of the body which can be very difficult to remove or treat in some cases (Nahmias et al. [8]).

Increased awareness of zoonotic infections has been found to influence the management and control of these diseases. However, lack of adequate knowledge by the communities on echinococcosis transmission has been linked to wide spread of the disease within and outside the communities in sub-Saharan African countries (John et al. [9]). Similarly, lack of knowledge by health staff on the diagnosis and treatment of $\mathrm{CE}$ has been found to be associated with poor management and control of the disease (Reyes et al. $[10])$. This has therefore contributed to underdiagnosis and reporting of zoonotic diseases thus culminating into poor disease monitoring coverage and lack of clear interventions to address the burden of zoonotic diseases (Reyes et al. [10]). An adequate information on knowledge, attitudes, and beliefs about echinococcosis by communities is therefore vital for them to play an important public health role (Otupiri et al. [11]). In addition, training of the health workers on the use of ultrasound for early diagnosis of CE is paramount. In Uganda, studies on the knowledge, beliefs, and attitudes of the communities and health workers about CE are scanty. It was against this background that this study was designed to determine the knowledge, attitudes, and beliefs of communities and health staff about echinococcosis infection in selected pastoral and agropastoral regions of Uganda.

\section{Materials and Methods}

2.1. Study Design. This was a descriptive cross-sectional survey conducted from July 2012 to January 2014.

2.2. Setting. The study comprised pastoral region of Northeastern and agropastoral regions of Eastern and Central Uganda. The districts of Nakapiripirit, Amudat, Moroto, and Napak were randomly selected in Northeastern region, while the districts of Kumi and Bukedea were selected in Eastern region. Nakasongola district was selected in Central region. The details of the regions is as shown in Figure 1 [12].

The selection of these regions was based on the predominance of the pastoral production system (Karamoja subregion) or mixed crop-livestock production systems (Eastern and Central subregions), where there is a high prevalence of CE in humans (Magambo et al. [5]), livestock (Chamai et al. [4]), and dogs as previously reported (Inangolet et al. [6] and Oba et al. [7]). These are remote, hard to reach communities with poor health infrastructure and with no specific control programs for CE.

2.3. Study Population. It comprised communities and health staff. Only the nurses and paramedical staff from Health Centers IVs were identified to avoid bias because they all had the same level of education background.

The prevalence of $66.3 \%$ of echinococcosis which was found in dogs (Inangolet et al. [6]) was used for the determination of the sample size for KAPs. It was assumed that the prevalence of echinococcosis in dogs would reflect the same prevalence of echinococcosis in humans, since the dogs are the primary hosts. The sample size calculation was then done using the equation of Kish and Leshlie (Kirkwood [13]) for proportions in cross-sectional studies.

$n=\left(Z^{2} / d^{2}\right) P Q$, where $Z$ is the value of 1.96 ( $Z$ in normal distribution curve), $n$ is the required sample size, $p$ is the estimated prevalence of $\mathrm{CE}, Q=100-P$, and $d$ is the required precision (5\%). Using this equation, a total sample size of 1,200 individuals in all the regions was therefore computed. However, we interviewed a total of 1,235 respondents.

2.4. Data Collection Procedure. Pretested structured questionnaires were used to generate information from eligible participants. Community participants were conveniently mobilized with the assistance of the elders and local leaders and brought to trading centers which had been identified for interviews. Random sampling procedure was then used to select community respondents. The names of the respondents were written in small chits of paper and then folded. Names of those to be interviewed were then randomly picked. The health staffs were consecutively recruited from their health facilities. Participation was limited to those voluntarily willing to take part in the study. All the participants were interviewed after seeking their consent.

2.5. Data Analysis. The data were entered and analyzed using software package for social sciences 10.0 (SPSS 10.0) [14]. The statistical differences between respondents on the knowledge, attitude, and beliefs about echinococcosis were compared using open source epidemiologic statistic soft ware program for public health version 2.2.1 (OPENEPI) using 2 $\times 2$ contingency tables [15]. Odds ratios and $95 \%$ confidence intervals were computed. A $p$ value of 0.05 was considered statistically significant.

\section{Results}

3.1. Sociodemographic Characteristics (Distribution) of Respondents. A total of 421 respondents were identified and interviewed in Northeastern region, 405 from Eastern region, and 409 from Central region, giving a total of 1,235 respondents, which was $2.9 \%$ a little more than the calculated sample size of 1,200. A total of 75 health workers were interviewed in all the regions giving an overall total of 1310 participants. A total of 720 males and 590 females were interviewed. 291 respondents from Northeastern region had informal education, 167 from Eastern region, and 187 from Central region. Their ages ranged between 18 and 80 years giving mean age of 49 years. The details of the sociodemographic characteristics are as shown in Table 1.

3.2. Community Knowledge about CE. The results showed that $60.8 \%$ of the respondents in Northeastern region (NE) were aware of CE infection compared with $24.2 \%$ in Eastern (OR 4.9, CI: 2.58-9.57, and $p<0.001$ ) and 21.3\% in Central regions (OR 5.8, CI: 3.0-11.6, and $p<0.001$ ). A significant difference was observed in the proportion of respondents who had heard of CE infection between Central and Eastern (E) region (OR 1.62, CI: 1.13-2.33, and $p<0.005)$. No differences were observed between Northeastern (NE) and $E$ 


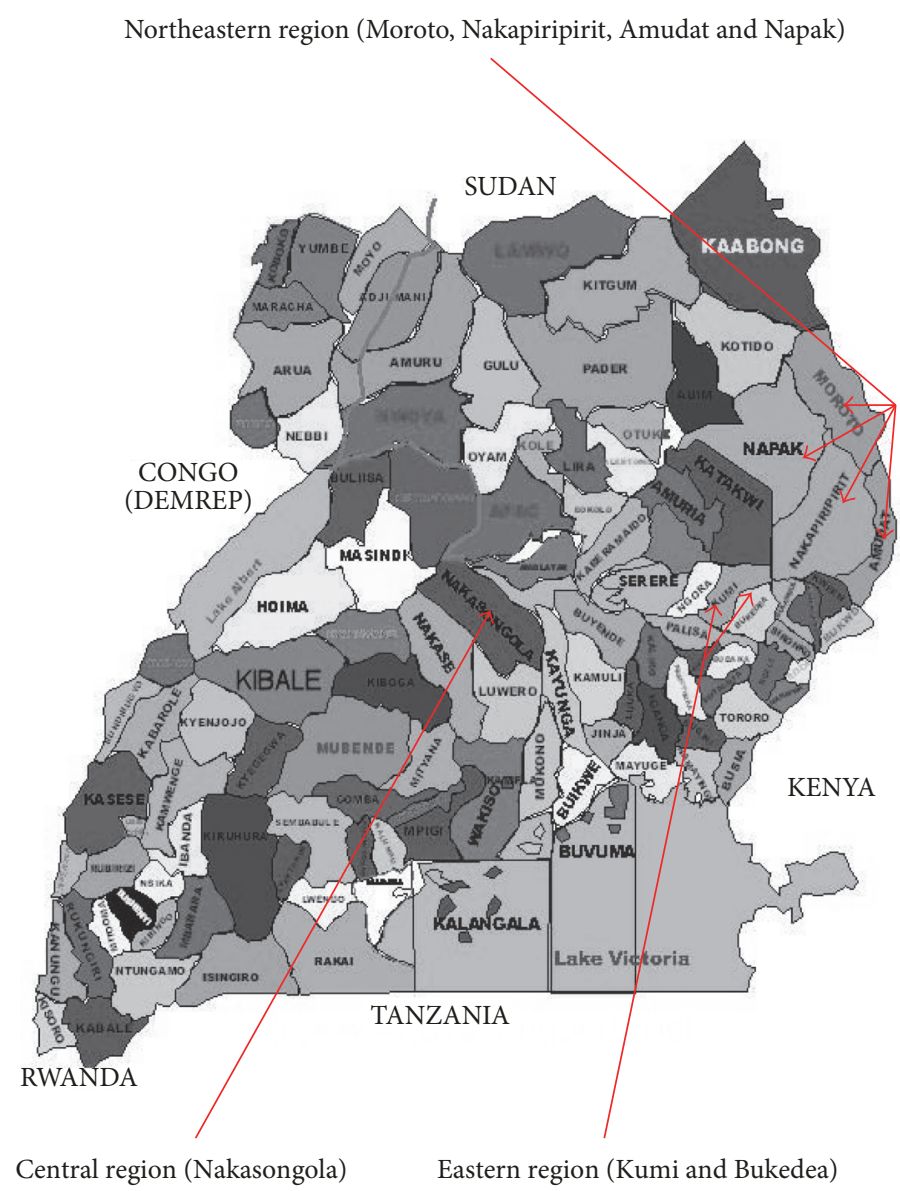

FIGURE 1: Map of Uganda showing the selected study regions.

TABLE 1: Sociodemographic characteristics (distribution) of respondents.

\begin{tabular}{|c|c|c|c|c|c|c|c|c|}
\hline \multirow{2}{*}{ Variable } & \multirow{2}{*}{ Category } & \multicolumn{2}{|c|}{ Northeastern } & \multicolumn{2}{|c|}{ Eastern } & \multicolumn{2}{|c|}{ Central } & \multirow{2}{*}{ Totals } \\
\hline & & Number & $(\%)$ & Number & $(\%)$ & Number & $(\%)$ & \\
\hline & Community Respondents & 421 & 34.1 & 405 & 32.8 & 409 & 33.1 & 1235 \\
\hline & Health staff & 20 & 26.7 & 26 & 34.7 & 29 & 38.6 & 75 \\
\hline \multirow{4}{*}{ Age (years) } & Below 18 & 54 & 32.1 & 65 & 38.7 & 49 & 29.2 & 168 \\
\hline & 21 to 40 & 233 & 33.5 & 224 & 32.2 & 238 & 34.2 & 695 \\
\hline & 41 to 60 & 31 & 33.6 & 123 & 31,5 & 136 & 34.9 & 390 \\
\hline & 60 to 80 & 23 & 40.4 & 19 & 33.3 & 15 & 26.3 & 57 \\
\hline \multirow{2}{*}{ Sex } & Male & 180 & 25.0 & 291 & 40.4 & 249 & 34.6 & 720 \\
\hline & Female & 261 & 42.2 & 140 & 23.7 & 189 & 32.0 & 590 \\
\hline \multirow{4}{*}{ Education level } & Informal & 291 & 45.3 & 167 & 25.9 & 185 & 28.8 & 643 \\
\hline & Primary & 125 & 24,6 & 200 & 39.3 & 184 & 36.1 & 509 \\
\hline & Secondary & 20 & 18.9 & 36 & 34.0 & 50 & 47.2 & 106 \\
\hline & Tertiary & 5 & 9.6 & 28 & 53.9 & 19 & 36.5 & 52 \\
\hline
\end{tabular}

or between NE and Central region ( $p>0.05$ ). Notably, 91.4\% of the respondents from Northeastern region claimed to have seen patients with CE signs compared with $23.4 \%$ and $19.5 \%$ from Eastern and Central region, respectively (OR 42.88; CI: 21.94-87.44; $p<0.001)$. None knew his/her CE status. The details are shown in Table 2.
The results in Table 2 show that respondents in Northeastern region were nearly five times more likely to have heard about $\mathrm{CE}$ than those in Eastern region $(\mathrm{OR}=4.9)$.

3.3. Knowledge of Communities about CE Infection according to the Level of Education. Notably, there was no statistical 
TABLE 2: Knowledge level of communities about CE infection in humans.

\begin{tabular}{|c|c|c|c|c|c|c|c|c|c|}
\hline \multirow{2}{*}{ Knowledge attribute } & \multirow{2}{*}{ Region } & \multicolumn{4}{|c|}{ Response } & \multirow{2}{*}{ Total } & \multirow{2}{*}{ OR } & \multirow{2}{*}{$95 \% \mathrm{CI}$} & \multirow{2}{*}{$p$ value } \\
\hline & & Yes $(n)$ & $(\%)$ & No $(n)$ & $\%$ & & & & \\
\hline \multirow{7}{*}{ Heard of CE } & Northeastern & 256 & 60.8 & 165 & 39.2 & 421 & \multirow{2}{*}{4.85} & \multirow{2}{*}{$3.60-6.60$} & \multirow{2}{*}{$0.001^{* *}$} \\
\hline & Eastern & 98 & 24.2 & 307 & 75.8 & 405 & & & \\
\hline & Northeastern & 256 & 60.8 & 165 & 39.2 & 421 & \multirow{2}{*}{5.73} & \multirow{2}{*}{$4.22-7.82$} & \multirow{2}{*}{$0.001^{* *}$} \\
\hline & Central & 87 & 21.3 & 322 & 78.7 & 409 & & & \\
\hline & Eastern & 98 & 24.2 & 307 & 75.8 & 405 & \multirow{2}{*}{1.18} & \multirow{2}{*}{$0.85-1.64$} & \multirow{2}{*}{0.321} \\
\hline & Central & 87 & 21.3 & 322 & 78.7 & 409 & & & \\
\hline & & & \multicolumn{7}{|c|}{ Only for those aware of $C E$} \\
\hline \multirow{6}{*}{ Known a CE tapeworm } & Northeastern & 7 & 1.7 & 249 & 98.3 & 256 & \multirow{2}{*}{0.52} & \multirow{2}{*}{$0.16-1.84$} & \multirow{2}{*}{0.295} \\
\hline & Eastern & 5 & 5.1 & 93 & 94.9 & 98 & & & \\
\hline & Northeastern & 7 & 2.7 & 249 & 98.3 & 256 & \multirow{2}{*}{1.19} & \multirow{2}{*}{$0.26-8.53$} & \multirow{2}{*}{0.878} \\
\hline & Central & 2 & 2.3 & 85 & 97.7 & 87 & & & \\
\hline & Eastern & 5 & 5.1 & 93 & 94.9 & 98 & \multirow{2}{*}{2.28} & \multirow{2}{*}{$0.44-17.32$} & \multirow{2}{*}{0.354} \\
\hline & Central & 2 & 2.3 & 85 & 97.7 & 87 & & & \\
\hline \multirow{6}{*}{ Had seen patients with CE signs } & Northeastern & 234 & 91.4 & 22 & 8.6 & 256 & \multirow{2}{*}{34.06} & \multirow{2}{*}{$18.22-65.94$} & \multirow{2}{*}{$0.001^{* *}$} \\
\hline & Eastern & 23 & 23.5 & 75 & 76.5 & 98 & & & \\
\hline & Northeastern & 234 & 91.4 & 22 & 8.6 & 256 & 42.88 & $21.94-7.44$ & $0.001^{* *}$ \\
\hline & Central & 17 & 19.5 & 70 & 80.5 & 87 & & & \\
\hline & Eastern & 23 & 23.4 & 75 & 76.5 & 98 & 1.44 & $0.71-2.95$ & 0.312 \\
\hline & Central & 17 & 19.5 & 70 & 80.5 & 87 & & & \\
\hline Only for those aware & & & & & & & & & \\
\hline & Northeastern & None & & & & & & & \\
\hline Know their CE status & Eastern & None & & & & & & & \\
\hline & Central & None & & & & & & & \\
\hline
\end{tabular}

NS $=p>0.05$ not significant, $p<0.05$ significant, ${ }^{* *} p<0.01$ highly significant, and $p<0.001$ very highly significant. OR $=$ odds ratio and CI $=$ confidence interval.

difference in the awareness about CE between the respondents with informal and primary education in Northeastern and Central regions $(p>0.05)$. Similarly, there was no statistical difference in the awareness about CE between the respondents with secondary and tertiary education in all the regions of Uganda ( $p>0.05 \%)$. However, the respondents with secondary and tertiary education were more aware about $\mathrm{CE}$ infection than those with informal and primary education in all the regions $(p<0.001)$. The details are as shown in Table 3.

The findings in Table 3 show that although there was high statistical difference between respondents with low and high level of education in the regions because of the differences in numbers, it is most unlikely that persons with high level of education would be more aware of CE than those with low level of education (OR less than 1).

3.4. Knowledge of Communities about CE Infection according to Sex. There was no statistical difference in the awareness about $\mathrm{CE}$ between male and female respondents in all the study regions $(p>0.05)$.

3.5. Health Workers Knowledge about Echinococcosis. Ninety percent of the health staff from Northeastern region and 96.2\% and 93.1\% from Eastern and Central regions, respectively, were aware of CE $(p>0.05) .57 .7$ percent of the health staff from Eastern region claimed to have seen patients with CE compared with $80.0 \%$ from Northeastern region $(p<$ 0.05).

None of the health staffs knew how to screen for CE and knew his/her CE status. The details are shown in Table 4.

Although the results in Table 4 show that there was no statistical difference between health workers in all the study regions as far as their level of knowledge about CE was concerned, respondents from Northeastern region were nearly two times more likely to see tape worm than those from Central region $(\mathrm{OR}=2.07)$.

3.6. Attitudes of the Communities towards the Screening and Treatment for Cystic Echinococcosis. $32.1 \%$ of the community participants from Northeastern region and 35.0\% from Central region had a positive attitude towards going to hospital for treatment compared with $60.5 \%$ from Eastern region $(p<0.001)$. Twenty percent $(19.8 \%)$ from Eastern region had positive attitude towards visiting witch doctors for treatment compared to $62.0 \%$ and $60.4 \%$ of the respondents from Northeastern and Central region, respectively (OR 6.61; CI: 4.81-9.81; $p<0.001$ and OR 6.18; CI: 4.52-8.48; $p<0.001$, resp.). The details are shown in Table 5.

The results in Table 5 show that respondents in Northeastern and Central regions were six times more likely to visit witch doctor for $\mathrm{CE}$ treatment than those from Eastern region 
TABLE 3: Knowledge of communities about CE infection according to the level of education.

\begin{tabular}{|c|c|c|c|c|c|c|c|c|}
\hline \multirow{2}{*}{ Region } & \multirow{2}{*}{ Number } & \multicolumn{4}{|c|}{ Heard about CE } & \multirow{2}{*}{ OR } & \multirow{2}{*}{$95 \% \mathrm{CI}$} & \multirow{2}{*}{$p$ value } \\
\hline & & Yes & $(\%)$ & No & $(\%)$ & & & \\
\hline \multicolumn{9}{|l|}{ Northeastern (421) } \\
\hline Informal & 278 & 123 & 44.2 & 155 & 55.8 & \multirow{2}{*}{0.78} & \multirow{2}{*}{$0.44-1.34$} & \multirow{2}{*}{0.355} \\
\hline Primary & 119 & 60 & 50.4 & 59 & 49.6 & & & \\
\hline Informal & 278 & 123 & 44.2 & 155 & 55.8 & \multirow{2}{*}{0.27} & \multirow{2}{*}{$0.14-0.50$} & \multirow{2}{*}{0.001} \\
\hline Secondary & 19 & 15 & 78.9 & 4 & 21.1 & & & \\
\hline Informal & 278 & 123 & 44.2 & 255 & 55.8 & \multirow{2}{*}{0.20} & \multirow{2}{*}{$0.10-0.37$} & \multirow{2}{*}{0.001} \\
\hline Tertiary & 5 & 4 & 80.0 & 1 & 20.0 & & & \\
\hline Primary & 119 & 60 & 50.4 & 59 & 49.6 & \multirow{2}{*}{0.21} & \multirow{2}{*}{$0.11-0.39$} & \multirow{2}{*}{0.001} \\
\hline Secondary & 19 & 15 & 78.9 & 4 & 21.1 & & & \\
\hline Primary & 119 & 60 & 50.4 & 59 & 49.6 & \multirow{2}{*}{0.26} & \multirow{2}{*}{$0.13-0.48$} & \multirow{2}{*}{0.001} \\
\hline Tertiary & 5 & 4 & 80.0 & 1 & 20.0 & & & \\
\hline Secondary & 19 & 15 & 78.9 & 4 & 21.1 & \multirow{2}{*}{0.94} & \multirow{2}{*}{$0.47-1.87$} & 0.850 \\
\hline Tertiary & 5 & 4 & $(80.0)$ & 1 & 20.0 & & & 0.050 \\
\hline Central (409) & & & & & & & & \\
\hline Informal & 173 & 18 & 10.4 & 155 & 89.6 & 0.66 & $0.27-1.57$ & 0.353 \\
\hline Primary & 172 & 24 & 14.0 & 148 & 86.0 & & & \\
\hline Informal & 173 & 18 & 10.4 & 155 & 89.6 & 0.04 & $0.03-0.12$ & 0.001 \\
\hline Secondary & 46 & 34 & 73.9 & 12 & 26.1 & 0.04 & $0.0 J-0.12$ & 0.001 \\
\hline Informal & 173 & 18 & 10.4 & 155 & 89.6 & 0.03 & $0.01-0.11$ & 0.001 \\
\hline Tertiary & 18 & 14 & 77.8 & 2 & 22.2 & 0.03 & $0.01-0.11$ & 0.001 \\
\hline Primary & 172 & 24 & 14.0 & 148 & 86.0 & 0.06 & $0.05-0.19$ & 0.001 \\
\hline Secondary & 46 & 34 & 73.9 & 12 & 26.1 & 0.06 & $0.05-0.19$ & 0.001 \\
\hline Primary & 172 & 24 & 14.0 & 148 & 86.0 & 0.03 & $0.01-0.15$ & 0.001 \\
\hline Tertiary & 18 & 14 & 77.8 & 2 & 22.2 & 0.00 & $0.01-0.15$ & 0.001 \\
\hline Secondary & 46 & 34 & 73.9 & 12 & 26.1 & 0.79 & $0.41-1.52$ & 0.484 \\
\hline Tertiary & 18 & 14 & 77.8 & 4 & 22.2 & 0.19 & $0.41-1.52$ & 0.484 \\
\hline Eastern $(n=405)$ & 405 & & & & & & & \\
\hline Informal & 157 & 16 & 10.2 & 141 & 89.8 & 0.43 & $0.20-0.92$ & 0.001 \\
\hline Primary & 188 & 35 & 18.6 & 153 & 81.4 & & & \\
\hline Informal & 157 & 16 & 10.2 & 141 & 89.8 & 0.03 & $0.01-0.08$ & 0.001 \\
\hline Secondary & 34 & 26 & 76.5 & 8 & 23.5 & 0.03 & $0.01-0.00$ & 0.001 \\
\hline Informal & 157 & 16 & 10.2 & 141 & 89.8 & 0.01 & $0.006-0.04$ & 0.001 \\
\hline Tertiary & 26 & 23 & 88.5 & 2 & 11.5 & 0.01 & $0.000-0.04$ & 0.001 \\
\hline Primary & 188 & 35 & 18.6 & 153 & 81.4 & 0.07 & $0.04-.15$ & 0.001 \\
\hline Secondary & 34 & 26 & 76.5 & 8 & 23.5 & 0.07 & $0.04-.13$ & 0.001 \\
\hline Primary & 188 & 35 & 18.6 & 153 & 81.4 & 0.03 & $0.01-0.06$ & 0.001 \\
\hline Tertiary & 26 & 23 & 88.5 & 3 & 11.5 & 0.05 & $0.01-0.00$ & 0.001 \\
\hline Secondary & 34 & 26 & 76.5 & 8 & 23.5 & 0.69 & $0.29-1.59$ & 0.389 \\
\hline Tertiary & 26 & 23 & 88.5 & 3 & 11.5 & 0.69 & $0.29-1.59$ & 0.389 \\
\hline
\end{tabular}

NS $=p>0.05$ not significant, $p<0.05$ significant, $p<0.01$ highly significant, and $p<0.001$ very highly significant. OR $=$ odds ratio; $C I=$ csonfidence interval. 
TABLE 4: Knowledge of the level of the health workers about CE infection.

\begin{tabular}{|c|c|c|c|c|c|c|}
\hline \multirow{2}{*}{ Knowledge attribute } & \multirow{2}{*}{ Region } & \multicolumn{2}{|c|}{ Response } & \multirow{2}{*}{ Totals } & \multirow{2}{*}{ OR (95\% CI) } & \multirow{2}{*}{$p$ value } \\
\hline & & Yes, $n(\%)$ & No, $n(\%)$ & & & \\
\hline \multirow{6}{*}{ Heard of CE } & Northeastern & $18(90.0)$ & $2(10.0)$ & 20 & \multirow{2}{*}{$0.37(0.12-5.15)$} & \multirow{2}{*}{0.238} \\
\hline & Eastern & $25(96.0)$ & $1(4.0)$ & 26 & & \\
\hline & Northeastern & $18(90.0)$ & $2(10.0)$ & 20 & \multirow{2}{*}{$0.67(0.07-6.95)$} & \multirow{2}{*}{0.361} \\
\hline & Central & $27(93.1)$ & $2(6.9)$ & 29 & & \\
\hline & Eastern & $25(96.2)$ & $1(3.8)$ & 26 & \multirow{2}{*}{$1.83(0.13-56.67)$} & \multirow{2}{*}{0.341} \\
\hline & Central & $27(93.1)$ & $2(6.9)$ & 29 & & \\
\hline \multirow{6}{*}{ Know a CE Tapeworm } & Northeastern & $15(75.0)$ & $5(25.0)$ & 20 & \multirow{2}{*}{$0.69(1.11-4.49)$} & \multirow{2}{*}{0.295} \\
\hline & Eastern & $22(84.6)$ & $4(15.4)$ & 26 & & \\
\hline & Northeastern & $15(75.0)$ & $5(25.0)$ & 20 & \multirow{2}{*}{$1.42(0.30-7.92)$} & \multirow{2}{*}{0.340} \\
\hline & Central & $21(72.4)$ & $8(27.6)$ & 29 & & \\
\hline & Eastern & $22(84.6)$ & $4(15.4)$ & 26 & \multirow{2}{*}{$2.07(0.45-11.27)$} & \multirow{2}{*}{0.354} \\
\hline & Central & $21(72.4)$ & $8(27.6)$ & 29 & & \\
\hline \multirow{6}{*}{ Had seen patients with CE signs } & Northeastern & $16(80.0)$ & $4(20.0)$ & 20 & \multirow{2}{*}{$0.19(0.02-0.96)$} & \multirow{2}{*}{$0.044^{*}$} \\
\hline & Eastern & $15(57.7)$ & $11(42.3)$ & 26 & & \\
\hline & Northeastern & $16(80.0)$ & $4(20.0)$ & 20 & \multirow{2}{*}{$1.80(0.31-14.82)$} & \multirow{2}{*}{0.273} \\
\hline & Central & $22(75.9)$ & $7(24.1)$ & 29 & & \\
\hline & Eastern & $15(57.7)$ & $11(42.3)$ & 26 & \multirow{2}{*}{$0.35(0.09-1.22)$} & \multirow{2}{*}{0.051} \\
\hline & Central & $22(75.9)$ & $7(24.1)$ & 29 & & \\
\hline \multicolumn{7}{|l|}{ Only for those aware of CE } \\
\hline \multirow{3}{*}{ Know how to screen for CE } & Northeastern & None & & & & \\
\hline & Eastern & None & & & & \\
\hline & Central & None & & & & \\
\hline \multirow{3}{*}{ Know their CE status } & Northeastern & None & & & & \\
\hline & Eastern & None & & & & \\
\hline & Central & None & & & & \\
\hline
\end{tabular}

NS $=p>0.05$ not significant, ${ }^{*} p<0.05$ significant, $\mathrm{OR}=$ odds ratio, and $\mathrm{CI}=$ confidence interval.

$(\mathrm{OR}=6.61$ and 6.18 , resp.). The results also show that although more respondents from Eastern region preferred hospital treatment for CE to witchcraft than those from Northeastern region, which was statistically significant, the likelihood that respondents from Eastern region would go to hospital was very low (OR less than 1).

\section{Attitudes of the Health Staff towards the Screening and Treatment for Cystic Echinococcosis}

There was no statistical difference between the health staff in all the study regions as far as their attitude towards echinococcosis screening and treatment was concerned $(p>$ $0.05)$.

4.1. Beliefs of the Communities about Cystic Echinococcosis. The study showed that $36.7 \%$ of the community respondents from Northeastern region and $15.3 \%$ from Eastern region believed that drinking raw milk and eating raw meat causes CE (OR 3.3; CI: 1.81-6.16; $p<0.00$ ). 43.9\% of the respondents from Eastern and $28.7 \%$ from Central region believed CE is caused by sharing shelter with animal compared to $11.7 \%$ from Northeastern region $(p<0.001)$. Similarly, 31.3\% of the respondents from Northeastern region believed CE is caused by witchcraft compared with $14.3 \%$ from Eastern region (OR 2.72; CI: $1.46-5.10 ; p<0.001$ ). Less than $3.4 \%$ of the respondents in all the regions believed CE is caused by eating food contaminated by dog fecal. The rest of the details are shown in Table 6.

The results in Table 6 show that respondents in Northeastern region were three times more likely to believe that $\mathrm{CE}$ is caused by drinking raw milk than those from Eastern region $(\mathrm{OR}=3)$.

4.2. Beliefs of the Health Workers about Cystic Echinococcosis. There was no statistical difference in the beliefs about CE infection between the health workers in all the regions $(p>$ 0.05).

4.3. Sources of Information of the Communities about Cystic Echinococcosis. Their main sources of information of the communities in all the regions about echinococcosis in descending order were traditional healers, elders in community and health workers, and hospitals/health centers.

4.4. Sources of Information of the Health Workers about Cystic Echinococcosis. Their main sources of information 
TABLE 5: Attitudes of the communities towards screening and treatment for CE infection.

\begin{tabular}{|c|c|c|c|c|c|c|c|c|c|}
\hline \multirow{2}{*}{ Attitude attribute } & \multirow{2}{*}{ Region } & \multicolumn{4}{|c|}{ Response } & \multirow{2}{*}{ Totals } & \multirow{2}{*}{ OR } & \multirow{2}{*}{$95 \% \mathrm{CI}$} & \multirow{2}{*}{$p$ value } \\
\hline & & Yes $(n)$ & $\%$ & No $(n)$ & $\%$ & & & & \\
\hline \multirow{6}{*}{$\begin{array}{l}\text { Willingness to be screened } \\
\text { (only those aware of CE) }\end{array}$} & Northeastern & 182 & 71.1 & 74 & 28.9 & 256 & \multirow{2}{*}{0.98} & \multirow{2}{*}{$0.58-1.68$} & \multirow{2}{*}{0.477} \\
\hline & Eastern & 70 & 71.1 & 28 & 28.6 & 98 & & & \\
\hline & Northeastern & 182 & 71.1 & 74 & 28.9 & 256 & \multirow{2}{*}{0.73} & \multirow{2}{*}{$0.14-1.29$} & \multirow{2}{*}{0.146} \\
\hline & Central & 67 & 77.0 & 20 & 23.0 & 87 & & & \\
\hline & Eastern & 70 & 71.1 & 28 & 28.6 & 98 & \multirow{2}{*}{0.73} & \multirow{2}{*}{$0.51-1.29$} & \multirow{2}{*}{0.146} \\
\hline & Central & 67 & 77.0 & 20 & 23.0 & 87 & & & \\
\hline \multirow{6}{*}{ Prefer hospital treatment } & Northeastern & 135 & 32.1 & 286 & 67.9 & 421 & \multirow{2}{*}{0.31} & \multirow{2}{*}{$0.23-0.41$} & \multirow{2}{*}{0.001} \\
\hline & Eastern & 245 & 60.5 & 160 & 40.0 & 405 & & & \\
\hline & Northeastern & 135 & 32.1 & 286 & 67.9 & 421 & \multirow{2}{*}{0.89} & \multirow{2}{*}{$0.66-1.17$} & \multirow{2}{*}{0.189} \\
\hline & Central & 143 & 35.0 & 266 & 65.0 & 409 & & & \\
\hline & Eastern & 245 & 60.5 & 160 & 40.0 & 405 & \multirow{2}{*}{2.85} & \multirow{2}{*}{$2.14-3.79$} & \multirow{2}{*}{0.001} \\
\hline & Central & 143 & 35.0 & 266 & 65.0 & 409 & & & \\
\hline \multirow{6}{*}{ Go to witch doctors } & Northeastern & 261 & 62.2 & 160 & 38.0 & 421 & \multirow{2}{*}{6.61} & \multirow{2}{*}{$4.81-9.08$} & \multirow{2}{*}{0.001} \\
\hline & Eastern & 80 & 19.8 & 325 & 80.2 & 405 & & & \\
\hline & Northeastern & 261 & 62.0 & 160 & 38.0 & 421 & \multirow{2}{*}{1.07} & \multirow{2}{*}{$0.81-1.47$} & \multirow{2}{*}{0.318} \\
\hline & Central & 247 & 60.4 & 162 & 39.6 & 409 & & & \\
\hline & Eastern & 80 & 19.8 & 325 & 80.2 & 405 & 6.18 & $4.52-8.48$ & 0.001 \\
\hline & Central & 247 & 60.4 & 162 & 39.6 & 409 & & & \\
\hline
\end{tabular}

NS $=p>0.05$ not significant and $p<0.001$ very highly significant. $\mathrm{OR}=$ odds ratio and $\mathrm{CI}=$ confidence interval.

of the health staff in all the regions about echinococcosis in descending order were fellow health workers, hospitals/health centers, community, and traditional healers.

\section{Discussion}

This study was conducted to determine the knowledge gaps, beliefs, and attitudes of the communities and health workers about echinococcosis infection in pastoral region of Northeastern and agropastoral regions of Eastern and Central Uganda [12]. There was variability in the awareness, attitudes, and beliefs about CE among the respondents in the study regions. Our study found the pastoral communities in Northeastern communities to be more aware of CE than the agropastoral communities in Eastern and Central regions. However, this finding is not in agreement with the a study by Nyakarahuka et al. [16] which found awareness about CE in pastoral communities of Kasese in Western region to be low. The higher awareness about CE in pastoral communities noted in Northeastern region was probably influenced by the high prevalence of $3.9 \%$ of CE among the communities in this region as compared to $1.2 \%$ in Eastern and 2.7\% in Central region (Othieno et al. [3]). This finding is in agreement with the study by Li et al. [17], which noted that awareness about $\mathrm{CE}$ was high in areas that were endemic for CE. This could also be one of the likely reasons why most of the communities in Northeastern region claimed to have seen more persons with CE signs than those from Eastern and Central regions, which is in conformity with the study by Craig et al. [18] which found that communities where the prevalence of $\mathrm{CE}$ is high were more likely to come across persons with CE.

Although there was no statistical difference in the knowledge ability about tape worm between respondents from Eastern region and Central region and between Central region and Northeastern region concerned, the likelihood that respondents from Eastern region would know about $\mathrm{CE}$ worm would be higher than those from Central region (OR 2.28, $p<0.354$ ) (Table 2). Similarly, the likelihood that respondents from Northeastern region would know about CE worm would be higher than those from Central region, respectively (OR 1.19, $p<0.878$ ) (Table 2). There was little variation in the way the $\mathrm{CE}$ tapeworm was locally called among the respondents who claimed to know CE tape worm. Those from Northeastern and Eastern regions were all calling it "ecidait" generally meaning a worm. This is probably because communities from these regions shared the same migration (Okwi et al. [19]). Those respondents from Central region called it "enfana" also generally meaning worm.

While the findings of this study (Table 3) are in conformity with the study by Omadang et al. [20] which noted that the level of awareness increased with level of education, this study found that respondents from NE region, with high CE prevalence (Othieno et al. [3]), were more likely to be more aware of CE than those from Eastern and Central regions of low prevalence regardless of their level of education.

Notably, it was found that the difference in the awareness between male and female respondents in all the regions was marginal. This agrees with the study by Omrani et al. [21] which noted there was no statistical significance in the 
TABLE 6: Beliefs of the communities about cystic echinococcosis.

\begin{tabular}{|c|c|c|c|c|c|c|c|c|}
\hline \multirow{2}{*}{ Belief attributes } & \multirow{2}{*}{ Regional comparison } & \multicolumn{4}{|c|}{ Response } & \multirow{2}{*}{ OR } & \multirow{2}{*}{$95 \%$ CI } & \multirow{2}{*}{$p$ value } \\
\hline & & Yes $(n)$ & $\%$ & No $(n)$ & $\%$ & & & \\
\hline \multirow{6}{*}{$\begin{array}{l}\text { Only those aware of CE } \\
\text { CE is caused by punishment } \\
\text { from God }\end{array}$} & Northeastern & 96 & 37.5 & 160 & 62.5 & \multirow{2}{*}{1.85} & \multirow{2}{*}{$1.10-3.17$} & \multirow{2}{*}{0.019} \\
\hline & Eastern & 24 & 24.5 & 74 & 75,5 & & & \\
\hline & Northeastern & 96 & 37.5 & 160 & 62.5 & \multirow{2}{*}{1.14} & \multirow{2}{*}{$0.69-1.91$} & \multirow{2}{*}{0.620} \\
\hline & Central & 30 & 34.5 & 57 & 65.5 & & & \\
\hline & Eastern & 24 & 24.5 & 74 & 75.5 & \multirow{2}{*}{0.51} & \multirow{2}{*}{$0.26-0.98$} & \multirow{2}{*}{0.043} \\
\hline & Central & 30 & 34.5 & 57 & 65.5 & & & \\
\hline \multirow{6}{*}{$\begin{array}{l}\text { CE is caused by drinking raw } \\
\text { milk and eating raw meat. }\end{array}$} & Northeastern & 94 & 36.7 & 162 & 63.3 & \multirow{2}{*}{3.3} & \multirow{2}{*}{$1.81-6.16$} & \multirow{2}{*}{0.001} \\
\hline & Eastern & 15 & 15.3 & 83 & 84.7 & & & \\
\hline & Northeastern & 94 & 36.7 & 162 & 63.3 & \multirow{2}{*}{1.05} & \multirow{2}{*}{$0.63-1.75$} & \multirow{2}{*}{0.861} \\
\hline & Central & 31 & 35.6 & 56 & 64.4 & & & \\
\hline & Eastern & 15 & 15.3 & 83 & 84.7 & \multirow{2}{*}{0.32} & \multirow{2}{*}{$0.15-0.66$} & \multirow{2}{*}{0.001} \\
\hline & Central & 31 & 35.6 & 56 & 64.4 & & & \\
\hline \multirow{6}{*}{$\mathrm{CE}$ is caused by witch craft } & Northeastern & 80 & 31.3 & 176 & 68.7 & \multirow{2}{*}{2.72} & \multirow{2}{*}{$1.46-5.10$} & 0.001 \\
\hline & Eastern & 14 & 14.3 & 84 & 85.7 & & & 0.001 \\
\hline & Northeastern & 80 & 31.3 & 176 & 68.7 & 0.43 & $0.26-0.70$ & 0.001 \\
\hline & Central & 45 & 51.7 & 42 & 48.3 & 0.43 & $0.20-0.70$ & 0.001 \\
\hline & Eastern & 14 & 14.3 & 84 & 85.7 & 0.16 & $0.08-0.31$ & 0.001 \\
\hline & Central & 45 & 51.7 & 42 & 48.3 & 0.10 & $0.08-0.31$ & 0.001 \\
\hline & Northeastern & 30 & 11.7 & 226 & 88.3 & 0.17 & $0.10-0.30$ & 0.001 \\
\hline & Eastern & 43 & 43.9 & 55 & 56.1 & 0.17 & $0.10-0.50$ & 0.001 \\
\hline $\mathrm{CE}$ is caused by sharing shelter & Northeastern & 30 & 11.7 & 226 & 88.3 & 0.33 & $0.18-0.61$ & 0.001 \\
\hline with animal & Central & 25 & 28.7 & 62 & 71.3 & 0.35 & $0.18-0.01$ & 0.001 \\
\hline & Eastern & 43 & 43.9 & 55 & 56.1 & 1.93 & $1.05-3.60$ & 0.034 \\
\hline & Central & 25 & 28.7 & 62 & 71.3 & 1.90 & $1.00-5.00$ & 0.034 \\
\hline & Northeastern & 6 & 2.3 & 250 & 97.7 & 1.15 & $0.24-8.41$ & 0.912 \\
\hline & Eastern & 2 & 2.0 & 96 & 98.0 & 1.13 & $0.24-0.41$ & 0.712 \\
\hline CE is caused by eating food & Northeastern & 6 & 2.3 & 250 & 97.7 & 0.67 & $0.16-3.36$ & 0.597 \\
\hline contamination by dog fecal & Central & 3 & 3.4 & 84 & 96.6 & 0.07 & $0.10-5.30$ & וענסי \\
\hline & Eastern & 2 & 2.0 & 96 & 98.0 & 0.59 & $0.10-3.58$ & 0.593 \\
\hline & Central & 3 & 3.4 & 84 & 96.6 & & & \\
\hline
\end{tabular}

NS $=p>0.05$ not significant, $p<0.05$ significant, $p<0.01$ highly significant, and $p<0.001$ very highly significant. $\mathrm{OR}=$ odds ratio; $\mathrm{CI}=$ confidence interval.

awareness about CE between males and females in the same study population.

Whereas the health respondents in all the study regions were aware that $\mathrm{CE}$ can be screened and treated in hospital; surprisingly, none knew how to screen for $\mathrm{CE}$ and none had participated in the screening exercise for CE. This probably explains why none of the health workers and community members had been screened for CE and knew his/her CE status in spite of the fact that $\mathrm{CE}$ cases are present in these regions (Othieno et al. [3]). Our findings are in agreement with a study by Reyes et al. [10], which found that lack of knowledge of the health workers on the use of ultrasound for detection of CE was a likely major contributor of endemicity of CE since they are not treated. This was also noted by Nasrieh et al. [22] study, which observed that lack of knowledge of the health workers on the use of ultrasound for detection of echinococcosis was probably association with the spread of the disease in the community. A similar study by Dawit et al. [23] found lack of understanding about CE detection by health professionals was associated with poor management, control of $\mathrm{CE}$, and high transmission of $\mathrm{CE}$ in the communalities, since those with the disease were not being detected and treated. These observations are equally in agreement with a study by John et al. [9] which showed that lack of adequate knowledge by health workers on echinococcosis detection was associated with poor management and high prevalence of echinococcosis in sub-Saharan African countries.

The majority of the community respondents preferred going to witch doctors for treatment for CE. This is probably because none the health staff in these regions knew how to screen for CE (Tables 4 and 5). Our findings tally with 
the study by Karim [24] which noted that members of the communities were often seeking treatment for CE from traditional healers due to poor provision of health care.

Respondents in the study regions had divergent beliefs about the causes of $\mathrm{CE}$. The majority of the community participants in all the study regions believed CE is caused by drinking raw milk and eating raw meat. Few of the participants believed that CE is punishment from God and is due to witchcraft which was in conformity with the study by Nyakarahuka et al. [16]. While a study by Acosta-Jamett et al. $[25,26]$ found dog fecal as a risk factor for CE in Chile, most of the community respondents in this study did not believe that eating dog fecal-contaminated food was the key mode of CE transmission. This is in agreement with the findings by El Berbri et al. [27], which showed that most of the respondents had poor beliefs about the role of a dog in $\mathrm{CE}$ transmission. The same observation was made by Oba et al. [7] study, which found that most respondents had poor knowledge of CE transmission.

The main sources of information about CE infection among the communities in all the study regions were found to be traditional healers. This probably explains why most of the respondents in Northeastern and Central regions believed that $\mathrm{CE}$ is caused by witchcraft and were inclined towards traditional healers (witch doctors) for health services (Table 5).

\section{Limitations of the Study}

The participants were not interviewed from the households because some of these communities especially pastoral communities do not have permanent houses since they continuously move from one place to the other in such pasture. Participants' responses of CE disease were limited to only physical observations of CE signs and thus subjective interpretations of $\mathrm{CE}$ could have introduced errors in the study.

\section{Conclusions and Recommendations}

Communities in Northeastern region were more aware of CE than those from Eastern and Central regions, respectively. The majority of the communities in all regions were not aware that $\mathrm{CE}$ can be treated in hospital and can be caused by eating food contaminated by dog fecal. None of the health staff was screening for $\mathrm{CE}$ and none of the community respondents including health workers had been screened for $\mathrm{CE}$. Sensitizing the communities about $\mathrm{CE}$ and its detection and treatment is cardinal to the prevention and control of $\mathrm{CE}$. There is also need to train the health staff preferably radiographers on the use of ultrasound for detection of $\mathrm{CE}$ and have these services established at referral health facilities.

\section{Abbreviations}

MoH: $\quad$ Ministry of Health

ERC: $\quad$ Ethics and Research Committee

MUCVM: Makerere University College of Veterinary Medicine
EC: $\quad$ Ethical Council

DHO: District Health Officer

CAO: Chief Administrative Officer

DVO: District Veterinary Officer

LCs: Local Councils.

\section{Data Availability}

Data is available in hard copies and can be accessed on request.

\section{Ethical Approval}

The permission to carry out this study and disseminate its findings was obtained from the Ministry of Health $(\mathrm{MoH})$ Ethics and Research Committee (ERC) and Makerere University College of Veterinary Medicine, Animal Resources and Biosecurity (COVAB) Institutional Review Board (IRB).

\section{Consent}

Informed consent was obtained from all the participants before they were involved in the study.

\section{Disclosure}

Field activities clearance was sought from the District Health Officer (DHO), the Chief Administrative Officer (CAO), District Veterinary Officer (DVO), and Village Local Councils (LCs). All the data that was generated was treated with highest level of confidentiality.

\section{Conflicts of Interest}

The authors affirm that they have no conflicts of interest.

\section{Authors' Contributions}

Emmanuel Othieno designed the study, collected data from the field, managed and analyzed it, and participated in manuscript development and revision. Andrew Livex Okwi was responsible for study design, field data collection and data analysis, manuscript development, and reading of manuscript. Ezekiel Mupere was responsible for study design and manuscript reading. Peter Oba was responsible for study design, data analysis, and manuscript revision. Leonard Omadang was responsible for study design and manuscript revision. Michael Ocaido developed overall CE study concept, participated in study design, collected field data, and analyzed and revised data. All authors have read and approved the final manuscript.

\section{Acknowledgments}

The authors would like to acknowledge the contributions of the following: Ludwing Siefert, Eberhard Zeyhle, and District Health Officers, in charges of health centres, and District Veterinary Officers in the districts visited. 


\section{References}

[1] WHO, "The control of neglected zoonotic diseases, a route to poverty alleviation," in World Health Organization, Geneva, Switzerland, 2006.

[2] C. N. L. Macpherson, A. Spoerry, E. Zeyhle, T. Romig, and M. Gorfe, "Pastoralists and hydatid disease: An ultrasound scanning prevalence survey in east africa," Transactions of the Royal Society of Tropical Medicine and Hygiene, vol. 83, no. 2, pp. 243-247, 1989.

[3] E. Othieno, A. L. Okwi, E. Mupere et al., "Risk factors associated with cystic echinococcosis in humans in selected pastoral and agro-pastoral areas of Uganda," International Journal of One Health, vol. 3, pp. 1-6, 2017.

[4] M. Chamai, L. Omadang, J. Erume et al., "Identification of echinococcus granulosus strains using polymerase chain reaction-restriction fragment length polymorphism amongst livestock in moroto district, uganda," Onderstepoort Journal of Veterinary Research, vol. 83, no. 1, 2016.

[5] J. Magambo, E. Njoroge, and E. Zeyhle, "Epidemiology and control of echinococcosis in sub-Saharan Africa," Parasitology International, vol. 55, pp. S193-S195, 2006.

[6] F. O. Inangolet, D. Biffa, J. Opuda-Asibo, J. Oloya, and E. Skjerve, "Distribution and intensity of Echinococcus granulosus infections in dogs in Moroto District, Uganda," Tropical Animal Health and Production, vol. 42, no. 7, pp. 1451-1457, 2010.

[7] P. Oba, F. Ejobi, L. Omadang et al., "Prevalence and risk factors of Echinococcus granulosus infection in dogs in Moroto and Bukedea districts in Uganda," Tropical Animal Health and Production, vol. 48, no. 2, pp. 249-254, 2016.

[8] J. Nahmias, R. Goldsmith, P. Schantz, M. Siman, and J. El-On, "High prevalence of human hydatid disease (Echinococcosis) in communities in northern Israel: Epidemiologic studies in the town of Yirka," Acta Tropica, vol. 50, no. 1, pp. 1-10, 1991.

[9] K. John, R. Kazwala, and G. S. Mfinanga, "Knowledge of causes, clinical features and diagnosis of common zoonoses among medical practitioners in Tanzania," BMC Infectious Diseases, vol. 8, article 162, 2008.

[10] M. M. Reyes, C. P. Taramona, M. Saire-Mendoza et al., "Human and canine echinococcosis infection in informal, unlicensed abattoirs in Lima, Peru," PLOS Neglected Tropical Diseases, vol. 6, no. 4, Article ID e1462, 2012.

[11] E. Otupiri, M. Adam, E. Laing, and B. D. Akanmori, "Detection and management of zoonotic diseases at the Kumasi slaughterhouse in Ghana," Acta Tropica, vol. 76, no. 1, pp. 15-19, 2000.

[12] “Images for Map districts of Uganda," https://en.wikipedia.org/ wiki/Districts_of_Uganda.

[13] B. R. Kirkwood, "Calculation of required sample size in Essentials and Medical Statistics," in Blackwell-Science LN, BlackwellScience LN, London, UK, 1988.

[14] SPSS Advanced Statistics 10.1. Chicago, SPSS Inc, 2000.

[15] K. M. Sullivan, A. Dean, and M. M. Soe, "OpenEpi: a web-based epidemiologic and statistical calculator for public health," Public Health Reports, vol. 124, no. 3, pp. 471-474, 2009.

[16] L. Nyakarahuka, M. Oryema-Lalobo, C. Kankya, L. Siefert, M. Ocaido, and F. Ejobi, "Knowledge, attitude and practices towards cystic echinococcosis in pastoral communities in Kasese district," Advance Tropical Medicine and Public Health International, vol. 2, no. 1, pp. 32-39, 2012.

[17] D. Li, Q. Gao, J. Liu et al., "Knowledge, attitude, and practices (KAP) and risk factors analysis related to cystic echinococcosis among residents in Tibetan communities, Xiahe County, Gansu Province, China," Acta Tropica, vol. 147, pp. 17-22, 2015.

[18] P. S. Craig, T. Li, J. Qiu et al., "Echinococcoses and tibetan communities," Emerging Infectious Diseases, vol. 14, no. 10, pp. 1674-1675, 2008.

[19] L. Okwi, W. Byarugaba, C. M. Ndugwa, A. Parkes, G. S. Bimenya, and E. Othieno, "Emergence of sickle cell gene through migration and intermarriage. A case study," Africa Journal of Animal and Biomedical Sciences, vol. 4, no. 1, pp. 4347, 2009.

[20] L. Omadang, M. Chamai, E. Othieno et al., "Knowledge, attitudes and practices towards cystic echinococcosis in livestock among selected pastoral and agro-pastoral communities in Uganda," Tropical Animal Health and Production, pp. 1-7, 2017.

[21] V. F. Omrani, S. Rouhani, B. Kazemi, S. J. Seyyedtabaei, F. Kheirandish, and M. Rezapour, "Seroprevalence of IgG antibodies against echinococcus granulosus by ELISA method using recombinant agb in Lorestan province, Western Iran," Iranian Journal of Public Health, vol. 46, no. 8, pp. 1132-1138, 2017.

[22] M. A. Nasrieh, S. K. Abdel-Hafez, S. A. Kamhawi, P. S. Craig, and P. M. Schantz, "Cystic echinococcosis in Jordan: socioeconomic evaluation and risk factors," Parasitology Research, vol. 90, no. 6, pp. 456-466, 2003.

[23] G. Dawit, F. Aklilu, T. Gebregergs, A. Hasen, and T. Ykealo, "Knowledge, attitudes and Practices of hydatidosis in pastoral community in relation to public health risk in Ayssaita, Northeastern of Ethiopia," Global Veterinaria, vol. 11, no. 3, pp. 272279, 2013.

[24] M. F. Karim, E. Brunetti, S. Rahman et al., "Abdominal cystic echinococcosis in Bangladesh: A hospital-based study," The Journal of Infection in Developing Countries, vol. 9, no. 1, pp. 070075, 2015.

[25] G. Acosta-Jamett, S. Cleaveland, A. A. Cunningham, and B. M. D. Bronsvoort, "Demography of domestic dogs in rural and urban areas of the Coquimbo region of Chile and implications for disease transmission," Preventive Veterinary Medicine, vol. 94, no. 3-4, pp. 272-281, 2010.

[26] G. Acosta-Jamett, T. Weitzel, B. Boufana et al., "Prevalence and Risk Factors for Echinococcal Infection in a Rural Area of Northern Chile: A Household-Based Cross-Sectional Study," PLOS Neglected Tropical Diseases, vol. 8, no. 8, p. e3090, 2014.

[27] I. El Berbri, M. J. Ducrotoy, A.-F. Petavy et al., "Knowledge, attitudes and practices with regard to the presence, transmission, impact, and control of cystic echinococcosis in Sidi Kacem Province, Morocco," Infectious Diseases of Poverty, vol. 4, no. 1, article no. 48, 2015. 


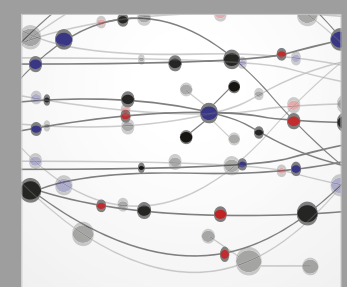

The Scientific World Journal
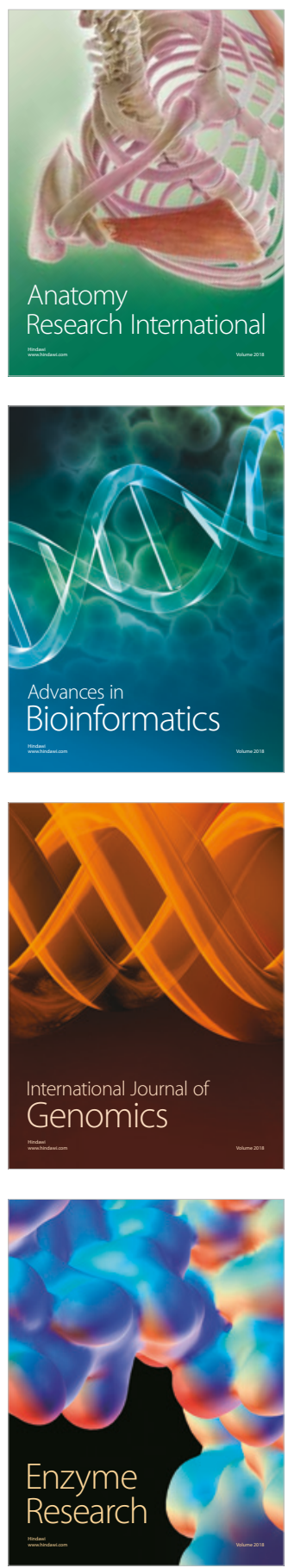
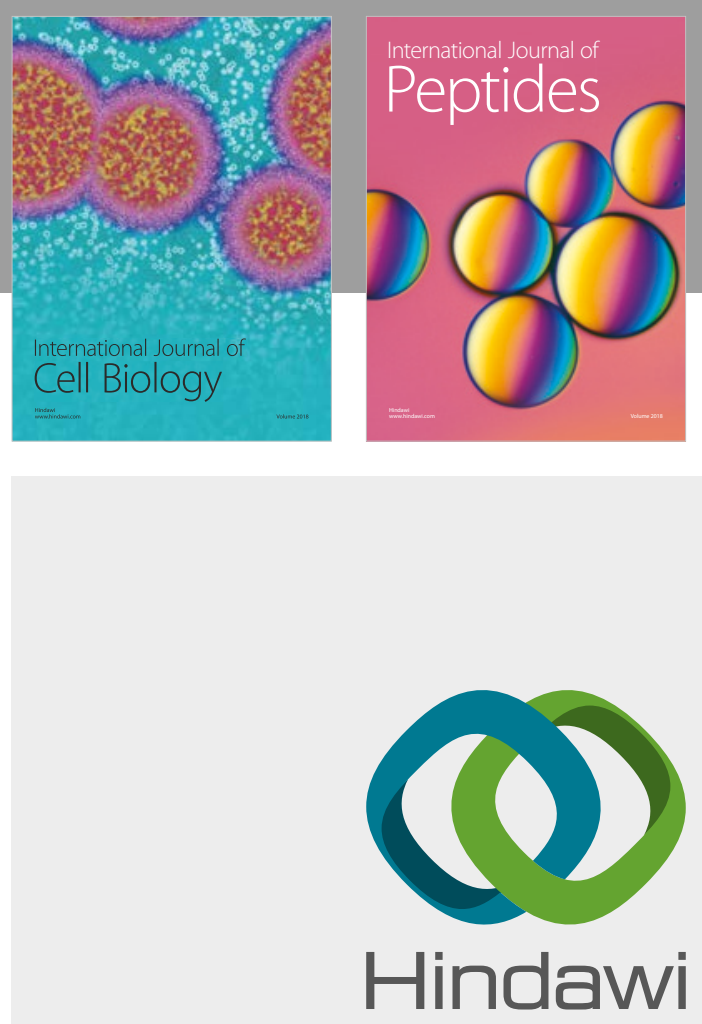

Submit your manuscripts at

www.hindawi.com
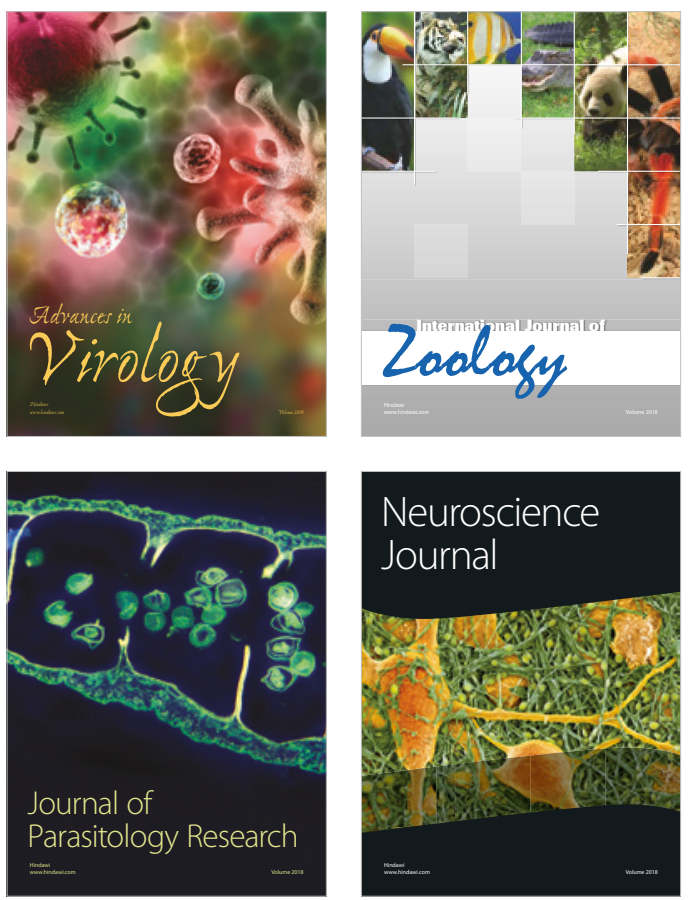
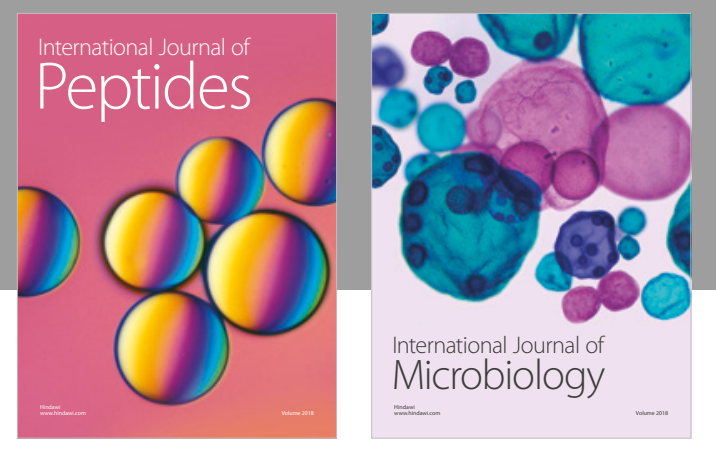

nternational Journal of Microbiology
Journal of
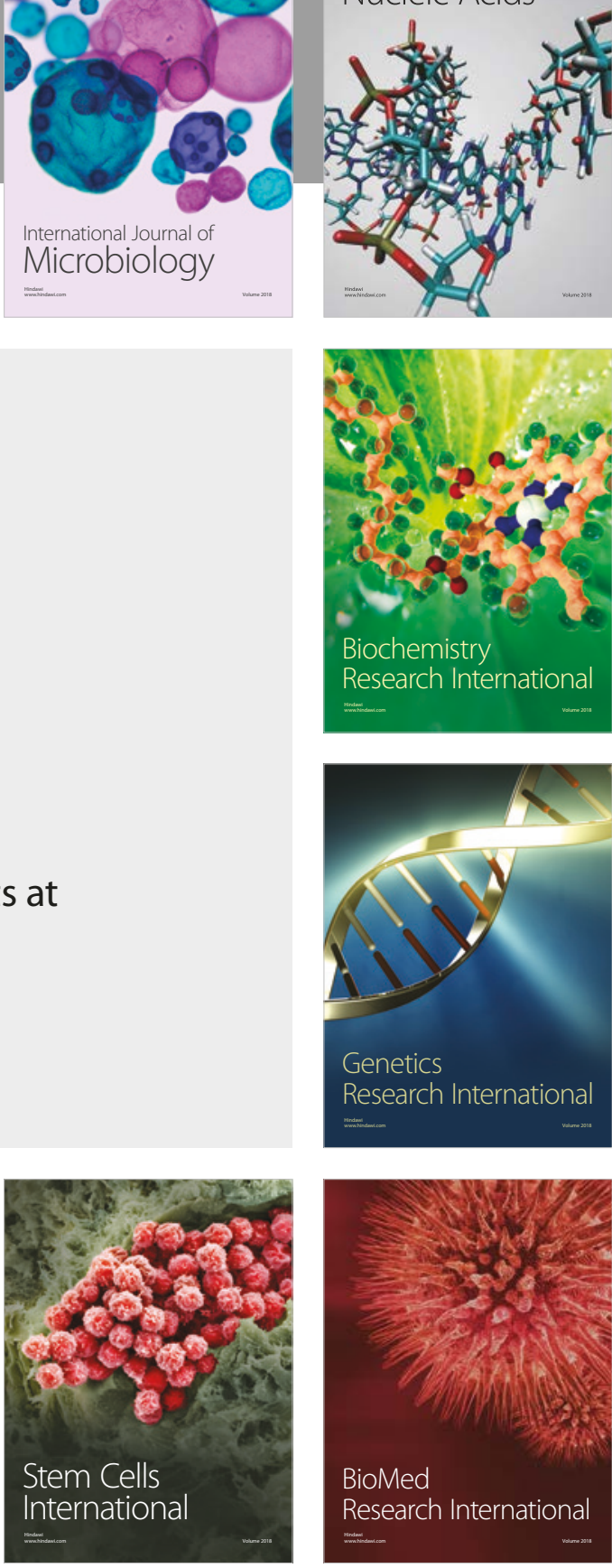
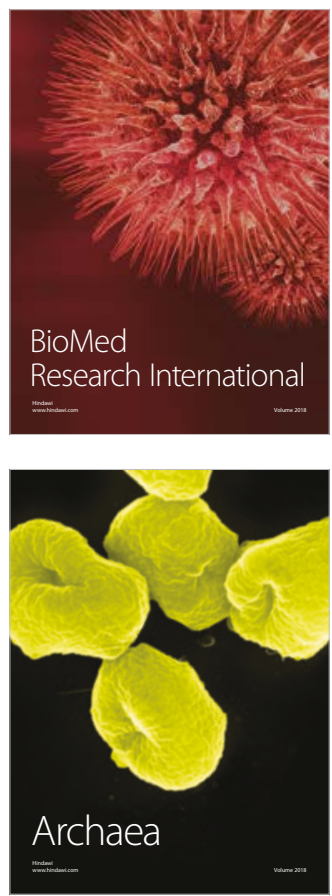